\title{
ESTUDO COMPARATIVO DE PARÂMETROS AMBIENTAIS METEOROLÓGICOS NA ÁREA URBANA DE PARAGOMINAS - PA
}

\author{
Carlos Otávio Rodrigues dos Santos; Cleiciane Silva da Conceição; Ronilson Rosário Lobo; \\ Antonio Pereira Júnior; Edmir dos Santos Jesus.
}

DOI: $10.4322 / 978-85-455202-1-4-01$

\section{INTRODUÇÃO}

A partir da segunda metade do século XX, os países ditos subdesenvolvidos passaram por uma fase de rápida e desorganizada industrialização, a qual intensificou o processo de crescimento urbano intenso e sem planejamento, que teve como consequência uma diversidade de impactos ambientais como resposta à ocupação e às atividades antrópicas, dentre os quais se destaca a alteração do clima urbano (MARTINI et al., 2014a).

Ademais, a falta de vegetação é um dos principais responsáveis pelas alterações do clima nos grandes centros urbanos, uma vez que as propriedades de regulação e melhoria do clima que as árvores oferecem são uma característica fundamental para garantir um clima urbano ideal. A influência da vegetação se manifesta nas mais variadas escalas climáticas, porém, para a configuração urbana de um lugar, o clima urbano tem na escala microclimática seu principal grau de interferência. A presença da vegetação nas áreas urbanas cria um microclima que difere daquele das áreas não vegetadas (MARTINI et al., 2014b).

Nesse sentido, sabe-se que locais com solo exposto e seco, tendem a temperaturas mais elevadas e umidade relativa mais reduzida, se comparadas àqueles ambientes com uma cobertura vegetal mais preservada e, consequentemente, mais úmidos (GALVANI et al., 2009), ou seja, a umidade relativa do ar é influenciada por alguns importantes parâmetros climáticos como a temperatura, mesmo que não ocorra aumento ou diminuição em seu conteúdo de umidade. Ou seja, é inversamente proporcional ao ponto de saturação e a temperatura (FALCÃO et al., 2010)

Dessa forma, a mesma pode ser influenciada por diversos controles e atributos climáticos como, por exemplo, a temperatura do ar, altitude, correntes oceânicas e uso do solo e cobertura vegetal de uma determinada região (MORAES et al., 2016). Os principais elementos meteorológicos que condicionam o comportamento dos seres humanos são: temperatura e umidade do ar, evaporação, a qual relaciona-se com a precipitação; velocidade do vento e radiação. A combinação destes elementos e os mecanismos fisiológicos fazem com que o principal condicionante para conforto térmico seja a combinação temperatura e umidade do ar (BURYOL et al., 2015).

A região Amazônica apresenta médias anuais de umidade relativa altas, fator este que se relaciona com a alta taxa de recarga hídrica, onde a precipitação anual em regiões próximas do equador, é geralmente superior a 2.000 milímetros. A região da foz do rio Amazonas e o setor noroeste da Amazônia apresentam precipitação anual superior a 3.000 milímetros. A precipitação diminui do equador para as regiões subtropicais e para o nordeste do Brasil, onde se observam valores anuais inferiores a 1.000 milímetros (LIMBERGER; SILVA, 2016).

Portanto, esse tipo de pesquisa justifica-se do ponto de vista das transformações pelas quais passaram o município de Paragominas nas últimas décadas em relação à expansão e diversificação das estruturas e dinâmica urbanas, e pelas possíveis consequências desse processo nas características atmosféricas locais.

Dessa forma, o objetivo do trabalho foi fazer um levantamento comparativo sobre o acumulado diário de precipitação pluvial, temperatura e UR, entre os dados da estação meteorológica automática (EMA), da Universidade do Estado do Pará (UEPA), que está localizada na UEPA Campus VI, no município de Paragominas, e os dados da EMA do Instituto Nacional de Meteorologia (INMET), os quais servem de fontes oficiais para diversos trabalhos, de forma a compreender as disparidades proporcionadas pela distância entre um ponto de coleta e outro. 


\section{METODOLOGIA}

O método de abordagem utilizado foi o dedutivo, pois o estudo parte das teorias e leis consideradas gerais e universais (estudos dos parâmetros ambientais meteorológicos) e busca explicar a ocorrência de fenômenos particulares (análise dos dados meteorológicos). Quanto ao método de procedimento, o utilizado foi o monográfico, que consiste no estudo de um caso que pode ser considerado representativo de casos semelhantes, de modo a observar os fatores que o influenciam, em similaridade com o escrito por Prodanov e Freitas (2013).

Em relação à pesquisa, ela apresenta abordagem quantitativa com natureza aplicada, que objetiva gerar conhecimentos para aplicações práticas dirigidas à solução de problemas específicos, como descrito por Sakamoto e Silveira (2014).

O levantamento de dados foi realizado por meio das EMA's de uso do IMET e da UEPA. Na EMA/UEPA os dados foram coletados no período de onze de abril à dez de maio de 2018, e em seguida tratados por meio do software Easywhether, próprio da estação. Na EMA/INMET os dados foram coletados através de fonte oficial, no do site da instituição www.inmet.gov.br/portal/. Em seguida, foram tiradas as médias diárias da umidade relativa do ar e de temperatura, e o acúmulo diário de precipitação.

A área de estudo está situada no município de Paragominas - PA, o qual possui a área de 19.342,25 quilômetros quadrados e população estimada em 111.764 habitantes (ANDRADE, 2011; IBGE, 2018). As EMA's localizam-se uma no bairro Angelim, mais precisamente na Universidade do Estado do Pará - UEPA, enquanto a outra se localiza às margens da PA - 256, na Universidade Federal Rural da Amazônia - UFRA. As duas distam entre si aproximadamente $5 \mathrm{~km}$ em linha reta (Figura 1). As coordenadas geográficas das EMA's do INMET e da UEPA são, respectivamente,

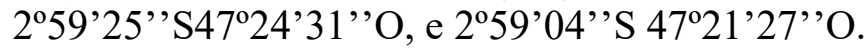

Figura 1- Área de localização das estações meteorológicas. Paragominas - PA.

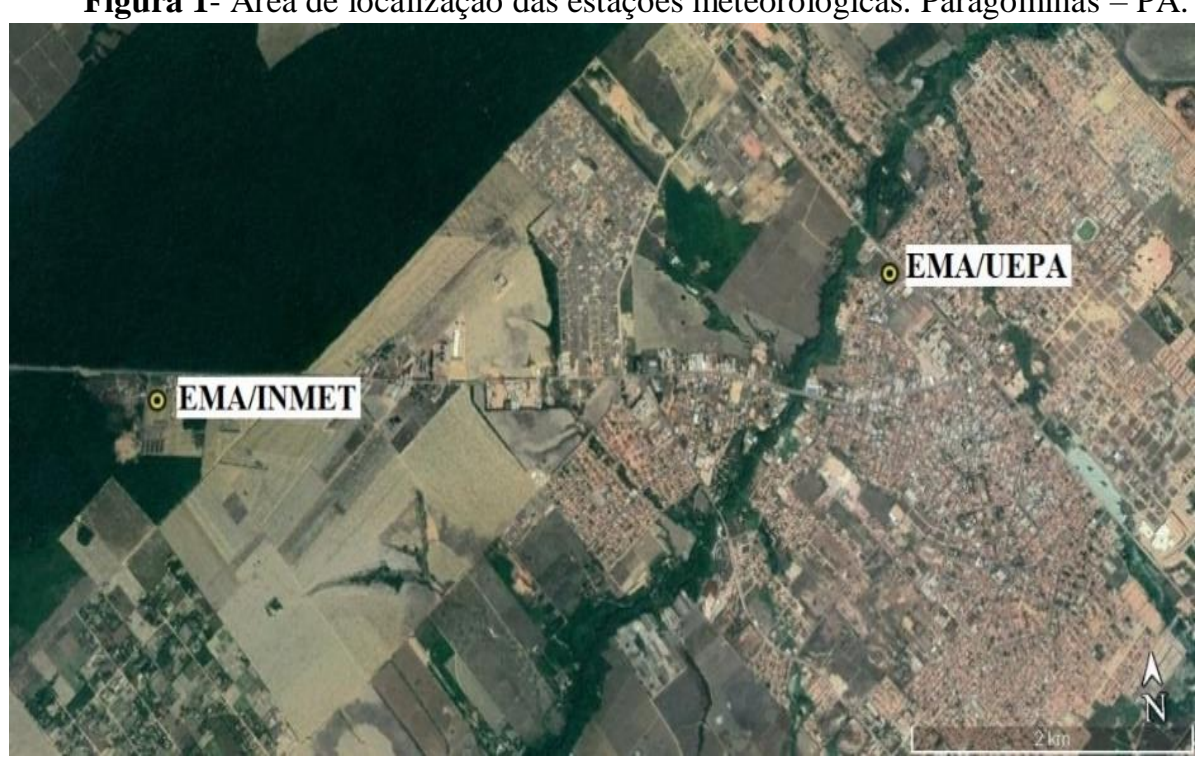

Fonte: autores (2018).

\section{RESULTADOS E DISCUSSÃO}

A seguir, observa-se os resultados da análise dos dados que contêm os parâmetros ambientais precipitação, temperatura do ar e umidade relativa do ar, as quais mensurou-se através das EMA/UEPA e EMA/INMET no período compreendido entre os dias 12 de abril e 10 de maio de 2018. 
Observa-se que houve grande variação da precipitação durante esse período, com acumulado diário nas estações da EMA/UEPA e EMA/INMET de, respectivamente, 23,16 mm e 14,83 mm. No dia 11 de abril, a EMA/UEPA mensurou o valor mais alto de acumulado de precipitação diária, que foi de 406,2 mm, e no mesmo dia a EMA/INMET mensurou 1,4 mm. A EMA/INMET mensurou o maior valor de acumulado de precipitação diário no dia 12 , que foi $151,4 \mathrm{~mm}$, no mesmo dia a EMA/UEPA mensurou 109,2 mm (Figura 2).

Figura 2 - Valores do acumulado diário de precipitação das EMA/UEPA e EMA/INMET.

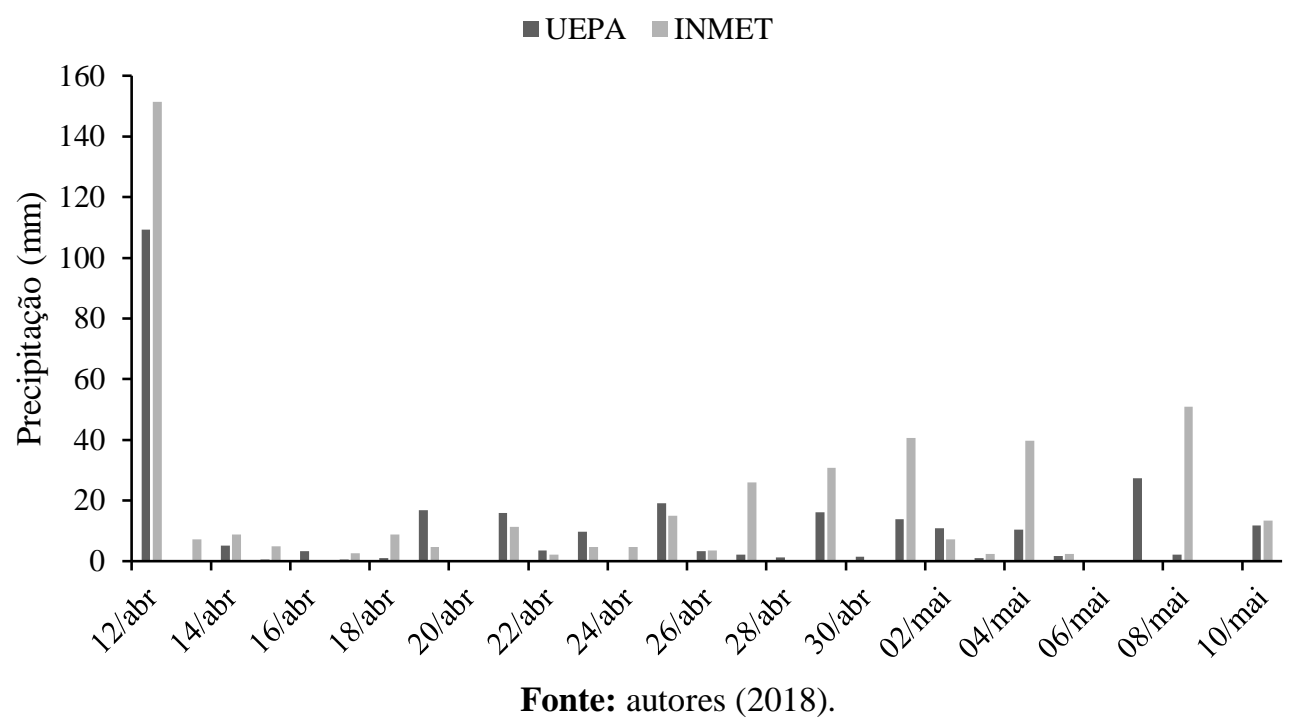

O pico de precipitação, que ocorreu no dia 11 na região da EMA/UEPA e no dia 12 na EMA/INMET, coincidiu com as fortes chuvas que provocaram o transbordamento do Rio Prainha e, consequentemente, a enchente na cidade de Paragominas em localidades próximas às margens do rio, durante a madrugada do dia 12.

Os valores do acumulado mensal de cada estação estão dispostos abaixo (Tabela 1). Na EMA/UEPA mensurou-se o acumulado de $288,6 \mathrm{~mm}$, e na EMA/INMET o acumulado mensal foi de $444 \mathrm{~mm}$, ou seja, a EMA/UEPA mensurou $61 \%$ a mais de precipitação durante o período analisado, consequência das fortes chuvas que caíram sobre a região da cidade, onde está localizada a EMA/UEPA.

Tabela 1 - Valores do acumulado mensal de precipitação e média mensal de temperatura. Paragominas - PA.

\begin{tabular}{ccc}
\hline $\begin{array}{c}\text { Localização da } \\
\text { EMA }\end{array}$ & $\begin{array}{c}\text { Acumulado de precipitação } \\
\text { mensal }(\mathrm{mm})\end{array}$ & $\begin{array}{c}\text { Média mensal de } \\
\text { precipitação }(\mathrm{mm})\end{array}$ \\
\hline UEPA & 288,6 & 9,95 \\
\hline INMET & 444 & 15 \\
\hline \multicolumn{3}{c}{ Fonte: autores (2018). }
\end{tabular}

Quanto às médias diárias de temperatura, a EMA/UEPA mensurou uma faixa de valores compreendidos entre $24{ }^{\circ} \mathrm{C}$ e $29^{\circ} \mathrm{C}$, com limite superior de $29,8^{\circ} \mathrm{C}$ no dia 20; a EMA/INMET mensurou uma faixa de valores compreendidos entre 23 graus $\mathrm{C}$ e $26^{\circ} \mathrm{C}$, com limite superior de $26,1^{\circ} \mathrm{C}$ no dia 15 . Sobre a tendência da variação na temperatura, foi efetuado um estudo no município de Curitiba - PR, por Martini et al. (2014b), e esses autores concluíram que a presença de vegetação em áreas urbanas cria um microclima que se difere de áreas não vegetadas, e reduz a temperatura do ar, enquanto aumenta a UR.

Nesse sentido, observou-se que a EMA/UEPA apresentou valores superiores aos mensurados pela EMA/INMET durante todo o período analisado, o que possivelmente ocorreu devido as diferenças de terreno onde as duas EMA's se localizam, informações que são corroboradas pelo autor 
antes citado. A EMA/INMET, por estar localizada na zona rural e próximo à área vegetada, mensurou valores de temperatura menor que a EMA/UEPA, localizada na zona urbana e próximo às construções de concreto. As médias mensais da EMA/UEPA e EMA/INMET foram, respectivamente, $27,6{ }^{\circ} \mathrm{C}$ e $25,3{ }^{\circ} \mathrm{C}$.

Figura 3 - Comparativo dos valores das médias diárias de temperatura durante o recorte temporal analisado. Paragominas - PA.
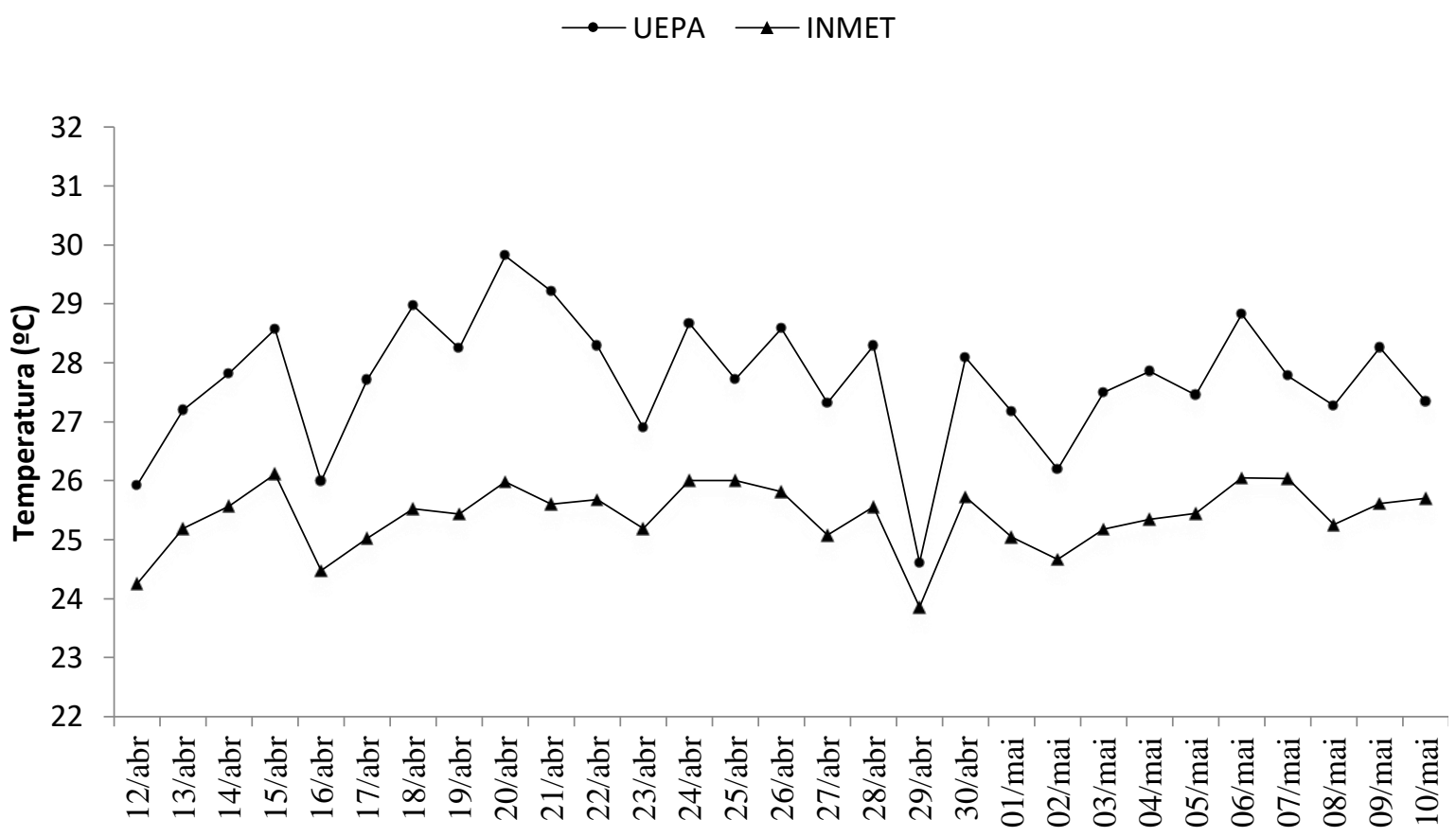

Fonte: autores (2018).

No que diz respeitos aos valores de UR (Figura 4), ambas EMA's tiveram valores máximos aproximados, porém o valor de pico foi mensurado no dia 29 pela EMA/INMET e igual a 97,1\%, enquanto que o maior valor de UR mensurado pela EMA/UEPA ocorreu no mesmo dia, e foi de $96,4 \%$, a média mensal na EMA/UEPA foi de $80,1 \%$ e na EMA/INMET foi $88,9 \%$.

Figura 4 - Comparativo dos valores das médias diárias de umidade relativa durante o recorte temporal analisado.

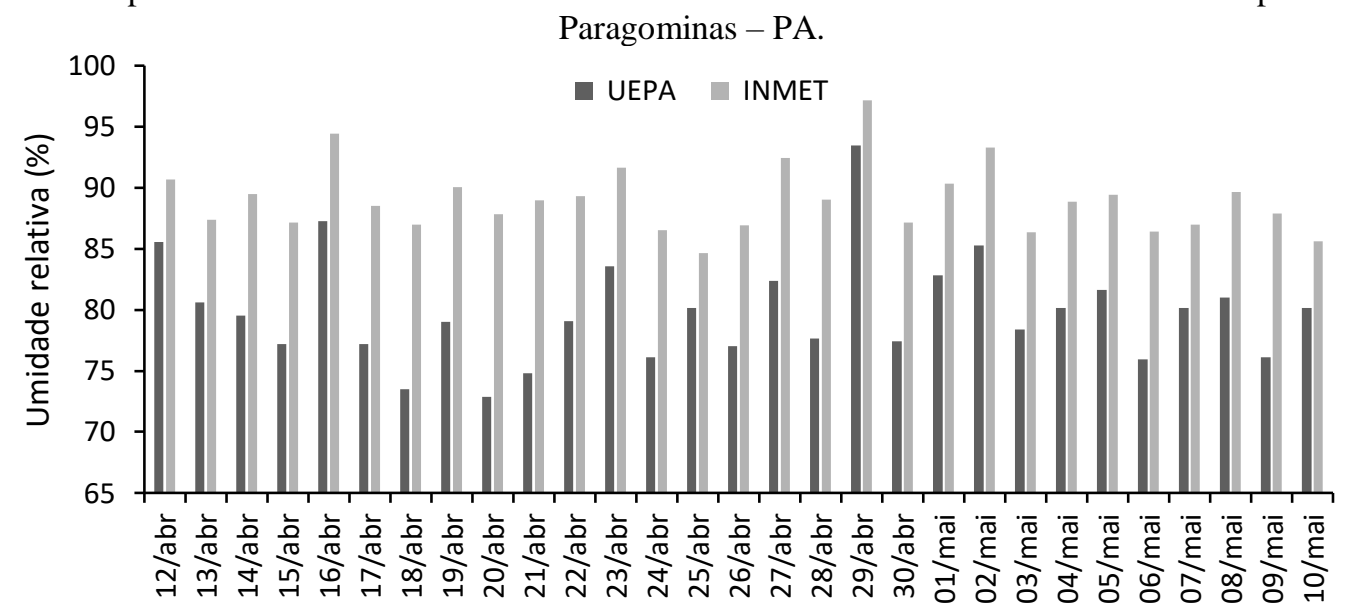

Fonte: autores (2018).

Nesse sentido, conforme afirma Galvani et al. (2009), em seu estudo no Parque Estadual de Intervales - SP, temperatura do ar e UR relacionam-se também com a densidade de vegetação presente 
no local, pois a temperatura tende a ser mais alta em locais onde o solo está sem cobertura vegetal, o que afeta inversamente a UR.

De modo inverso ao gráfico da temperatura, na Figura 3 podemos observar que, concomitantemente ao dia, todos os parâmetros de UR mensurados pela EMA/UEPA foram menores do que os mensurados pela EMA/INMET. Nesse sentido, a densidade de vegetação, que é maior nas proximidades desta última, pode ter sido o principal motivo de se ter o maior valor de UR na EMA/INMET.

\section{CONCLUSÃO}

A constituição de um ambiente agradável aos seres humanos por meio do conforto térmico é fundamental para o bem-estar físico e mental, além de propor um meio ambiente saudável no entorno. Portanto, foi possível notar a influência da vegetação e das unidades arquitetônicas nos valores dos dados mensurados pelas duas EMA's, onde a EMA/INMET apresentou valores que demonstram um maior conforto térmico, relação direta com a densidade de vegetação no seu entorno, que é superior à EMA/UEPA.

O conforto térmico influencia diretamente na produtividade das pessoas, daí a necessidade de se aumentar as áreas verdes, pois, como o presente trabalho demonstra, a presença de vegetação diminui a temperatura, e ameniza a sensação térmica devido ao aumento do albedo. Nesse sentido, o estado do Pará encontra-se na região oriental da Amazônia brasileira, lugar com um dos maiores índices de precipitação do país, o que gera altas médias de UR, porém por estar localizado na região dos trópicos, também apresenta altas taxas da radiação solar. Destaca-se ainda a importância de o estudo desses parâmetros ambientais de maneira entender o seu comportamento, e criar ambientes que sejam mais propícios ao desenvolvimento dos seres humanos.

\section{REFERÊNCIAS}

BURIOL, G. A.; ESTEFANEL, V.; BRESSAN, V. C.; RICHI, E. Z. Conforto térmico para os seres humanos nas condições de ambiente natural em Santa Maria, RS, Brasil. Ciência Rural, Santa Maria, v.45, n.2, p.223-230, fev. 2015.

FALCÃO, R. M. et al. Análise da Variação da Umidade Relativa do Ar do Pico Da Bandeira, Parque Nacional Alto Caparaó, BRASIL. Anais...VI Seminário Latino-Americano de Geografia Física, II Seminário Ibero-Americano de Geografia Física, Universidade de Coimbra, maio, 2010.

GALVANI, E. et al. Relação entre umidade relativa do ar, cobertura vegetal e uso do solo no Parque Estadual de Intervales (PEI) e seu entorno, São Paulo, Brasil. Anais... XXII Encuentro de Geógrafos de América Latina - EGAL 2009, Montevideo. 3 a 7 de abril de 2009.

LIMBERGER, L.; SILVA, M. E. S. Precipitação na bacia amazônica e sua associação à variabilidade da temperatura da superfície dos oceanos Pacífico e Atlântico: uma revisão. Geousp - Espaço e Tempo. v. 20, n. 3, p.657-675. 2016.

MARTINI, A. et al. Percepção da população sobre o conforto térmico proporcionado pela arborização de Ruas de Curitiba-PR. FLORESTA, Curitiba. v. 44, n. 3, p. 515 - 524. jul./set. 2014a.

MARTINI, A.; BIONDI, D.; ZAMPRONI, K. A percepção do conforto térmico em uma rua arborizada com ipê-amarelo. Anais... V Congresso Brasileiro de Gestão Ambiental. Belo Horizonte/MG - 24 a 27 de nov. 2014b. 
MORAES, S. L.; SANTOS, D. D.; GALVANI, E. Variação da umidade relativa do ar média e mínima no perfil topoclimático da trilha caminhos do mar (SP). Anais... XII Simpósio Brasileiro de Climatologia e Geografia - SBCG: VARIABILIDADE E SUSCEPTIBILIDADE CLIMÁTICA: Implicações Ecossistêmicas e Sociais, Goiânia. 25 a 29 de outubro de 2016.

PRODANOV, C. C.; FREITAS, E. C. Metodologia do Trabalho Científico: Métodos e Técnicas da Pesquisa e do Trabalho Acadêmico. $2^{a}$ ed. Novo Hamburgo: Feevale, 2013.

SAKAMOTO, C. K.; SILVEIRA, I. O. Como fazer projetos e Iniciação Científica. São Paulo: Paulus, 2014.

Carlos Otávio Rodrigues dos Santos Acadêmico de Engenharia Ambiental. Universidade do Estado do Pará Departamento de Engenharia Ambiental. otavio.eng.amb@gmail.com

Cleiciane Silva da Conceição Acadêmica de Engenharia Ambiental

Universidade do Estado do Pará Departamento de Engenharia Ambiental cleicesilva17.eng@gmail.com

Ronilson Rosário Lobo Acadêmico de Engenharia Ambiental. Universidade do Estado do Pará Departamento de Engenharia Ambiental. ronilsonlobo@gmail.com

Antônio Pereira Júnior Mestre em Ciências Ambientais. Universidade do Estado do Pará. Departamento de Engenharia Ambiental. antonio.junior@uepa.br

Edmir dos Santos Jesus

Doutor em Ciências Meteorológicas

Universidade do Estado do Pará. Departamento de Engenharia Ambiental. edmir.jesus@gmail.com 